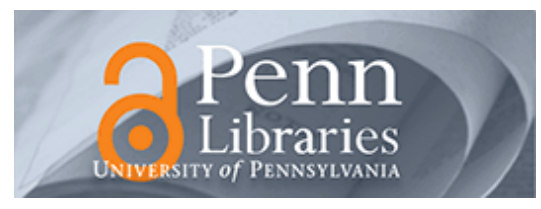

University of Pennsylvania

ScholarlyCommons

\title{
Multiple Dimensions of Family Involvement and Their Relations to Behavioral and Learning Competencies for Urban, Low-Income Children
}

John Fantuzzo

University of Pennsylvania, JOHNF@GSE.UPENN.EDU

Christine Michele McWayne

University of Pennsylvania

Marlo A Perry

University of Pennsylvania

Stephanie Childs

Follow this and additional works at: https://repository.upenn.edu/gse_pubs

Part of the Early Childhood Education Commons

\section{Recommended Citation}

Fantuzzo, J., McWayne, C., Perry, M., \& Childs, S. (2004). Multiple Dimensions of Family Involvement and Their Relations to Behavioral and Learning Competencies for Urban, Low-Income Children. School Psychology Review, 33 (4), 467-480. Retrieved from https://repository.upenn.edu/gse_pubs/438 


\title{
Multiple Dimensions of Family Involvement and Their Relations to Behavioral and Learning Competencies for Urban, Low-Income Children
}

\author{
Abstract \\ Relations between multiple dimensions of family involvement in early childhood education and classroom \\ outcomes were examined. Participants included 144 urban, Head Start children. Parental report of family \\ involvement was gathered in late fall using a multidimensional assessment. Relations between family \\ involvement dimensions and end of the year outcomes of approaches to learning, conduct problems, and \\ receptive vocabulary were investigated. Results revealed that Home-Based family involvement emerged \\ as the strongest predictor of child outcomes. This dimension associated significantly with children's \\ motivation to learn, attention, task persistence, receptive vocabulary skills, and low conduct problems. \\ The School-Based Involvement dimension was significantly related to low conduct problems in the \\ classroom when combined with the influence of Home- Based Involvement. The School-Based \\ Involvement and Home-School Conferencing dimensions did not predict later child outcomes when \\ considered simultaneously with Home-Based Involvement.
}

\section{Keywords}

involvement, competencies, urban, low-income

Disciplines

Early Childhood Education | Education 


\title{
Multiple Dimensions of Family Involvement and Their Relations to Behavioral and Learning Competencies for Urban, Low-Income Children
}

\author{
John Fantuzzo, Christine McWayne, and Marlo A. Perry \\ University of Pennsylvania \\ Stephanie Childs \\ School District of Philadelphia
}

\begin{abstract}
Relations between multiple dimensions of family involvement in early childhood education and classroom outcomes were examined. Participants included 144 urban, Head Start children. Parental report of family involvement was gathered in late fall using a multidimensional assessment. Relations between family involvement dimensions and end of the year outcomes of approaches to learning, conduct problems; and receptive vocabulary were investigated. Results revealed that Home-Based family involvement emerged as the strongest predictor of child outcomes. This dimension associated significantly with children's motivation to learn, attention, task persistence, receptive vocabulary skills, and low conduct problems. The School-Based Involvement dimension was significantly related to low conduct problems in the classroom when combined with the influence of HomeBased Involvement. The School-Based Involvement and Home-School Conferencing dimensions did not predict later child outcomes when considered simultaneously with Home-Based Involvement.
\end{abstract}

Family involvement in education has been identified as a beneficial factor in young children's learning (National Research Council [NRC], 2001; U.S. Department of Education, 2000). It is, therefore, a key component of national educational policies and early childhood programs. The National Education Goals Panel calls for schools to promote partnerships that will increase parental involvement and participation in supporting the social, emo- tional, and academic development of children. (1997). The NRC recommends that early childhood programs build relationships with parents to develop equally beneficial learning environments for young children at home and at school (2001). Given the greater educational risks that face young children living in poverty, parent involvement in education is especially important (NRC, 2001). The protective potential of parent involvement is recognized

This research project was supported by a Head Start/University Partnership grant from the U.S. Department of Health and Human Services to the first author and a Head Start Scholars grant to the third author. Special thanks go to our collaborators at Prekindergarten Head Start in the School District of Philadelphia: Director Jennifer Plumer Davis and her Head Start staff.

Correspondence concerning this article should be addressed to John Fantuzzo, Psychology in Education Division, Graduate School of Education, University of Pennsylvania, Philadelphia, Pennsylvania 19104; E-mail: johnf@gse.upenn.edu 
by Head Start, the nation's largest federally funded early intervention program for low-income children. Head Start's national performance standards require programs to promote parental participation in every. facet of their children's early educational experiences, from the daily activities of the classroom to program governance (U.S. Department of Health and Human Services [U.S. DHHS], 1998).

A developmental-ecological perspective provides a conceptual framework for the above mandates and policies. This perspective identifies the family system as the most influential and proximal system in children's early learning (Bronfenbrenner, 1992). It also recognizes the importance of establishing beneficial connections between families and schools (Christenson \& Sheridan, 2001). These connections are believed to foster children's development of key emergent skills necessary for school success (Pianta, Rimm-Kaufman, \& Cox, 1999; Rimm-Kaufmann \& Pianta, 2000). In accord, Head Start family involvement mandates are based on the assumption that parent participation in the program affects positively parenting behaviors and attitudes, which in turn mediate child development outcomes (Slaughter-Defoe \& Brown, 1998).

Much of the research on parent involvement, as it relates to children's outcomes, has emphasized the relationship between specific parent involvement behaviors and children's achievement. Parental involvement at school (e.g., with school activities, direct communication with teachers and administrators) is associated with greater achievement in mathematics and reading (Griffith, 1996; Reynolds, 1992; Sui-Chu \& Willms, 1996). Higher levels of parent involvement in their children's educational experiences at home (e.g., supervision and monitoring, daily conversations about school) have been associated with children's higher achievement scores in reading and writing, as well as higher report card grades (Epstein, 1991; Griffith, 1996; Sui-Chu \& Willms, 1996; Keith et al., 1998). Other research has shown that parental beliefs and expectations about their children's learning are strongly related to children's beliefs about their own competen- cies, as well as their achievement (Galper, Wigfield, \& Seefeldt, 1997).

However, few studies link parent involvement to preschool children's outcomes for vulnerable groups, such as low-income children. Research with this group has shown that parent involvement programs focusing on improving the home learning environment (through parent education, provision of materials, etc.) increases children's motivation and self-efficacy (Dickinson \& DeTemple, 1998; Mantzicopoulos, 1997; Parker, Boak, Griffin, Ripple, \& Peay, 1999). Parents who evidenced high levels of school contact (volunteering in the classroom, participating in educational workshops, attending Policy Council meetings) had children who demonstrated greater social competency than children of parents with lower levels of school contact (Parker et al., 1997).

Although family involvement is conceptualized as a complex, multifaceted construct (Epstein, 1995; Fantuzzo, Tighe, \& Childs, 2000), most of this early childhood research investigates isolated parent involvement behaviors. For example, many studies use surveys or solitary items from surveys to assess parent involvement (Griffith, 1996; Watkins, 1997). A few studies even use just one item (e.g., Reynolds, Mavrogenes, Bezruczko, \& Hagemann, 1996), which is inadequate to measure such a complex set of behaviors. To understand the relative effect of dimensions of family involvement in children's early educational experiences on children's competencies, multivariate study with empirically derived constructs is needed. Capturing the distinct multidimensional nature of family involvement will allow researchers to examine simultaneously the differential relationship between family involvement dimensions and a variety of early childhood competencies that are important to school success.

Fantuzzo and colleagues (2000) recently initiated a multivariate study of family involvement in early childhood. Using Epstein's typology of parent involvement behaviors (Epstein, 1995) with an early childhood population (preschool, kindergarten, and first grade students) of urban parents, this team of researchers developed a multidimensional scale 
of family involvement, the Family Involvement Questionnaire (FIQ; Fantuzzo et al., 2000). Research on the FIQ revealed three robust dimensions of parent-reported involvementHome-Based Involvement, School-Based Involvement, and Home-School Conferencingthat comported with major categories in the parent involvement research literature. These dimensions were evident across early childhood settings, including prekindergarten, kindergarten, and first grade and were supported by observed parental volunteer activities (Fantuzzo, Tighe, \& Perry, 1999).

To date, only one study has investigated the relationship between the FIQ dimensions and preschool outcomes, specifically, parent and teacher reports of interactive preschool, peer play behaviors (Fantuzzo et al., 1999). This study found that Home-Based Involvement was related to prosocial, peer play interactions both at home and at school. SchoolBased Involvement was associated with lower levels of disruptive peer play across the two contexts. Home-School Conferencing was not found to be related to peer play behaviors in either the home or the school setting. Although this study provided new information regarding the relationship of involvement behaviors to child outcomes, it was limited in terms of the scope of outcomes studied.

The purpose of the present study was to extend the previous cross-sectional examination of the relationship between dimensions of family involvement and peer play competencies in two ways. First, the relationship among multiple dimensions of family involvement assessed in the fall of the preschool year and preschool classroom competencies measured at the end of the year was studied. Second, a broader set of early childhood outcomes than peer play (including foundational approaches to learning, classroom conduct, and receptive vocabulary) were identified. These additional relevant competencies have been identified by the National Educational Goals Panel as key to school success for young children (Kagan, Moore, \& Bredekamp, 1995). It was hypothesized that home-based involvement would be most strongly associated with positive classroom learning outcomes and that direct school- based involvement would predict lower levels of conduct problems.

\section{Methods}

\section{Participants}

Participants in this study were 144 preschool children enrolled in central city Head Start centers in a large urban setting in the Northeast. Children ranged in age from 46 to 68 months $(M=58.9, S D=6.6)$, and $46 \%$ of the children in this study were male. Ninetysix percent of the participant families were African American and 4\% represented other ethnic groups (i.e., Caucasian, Asian, and Latino). Parent participants in this study ranged in age from 18 years to 74 years $(M=33, S D=$ 11.5). Additionally, $73 \%$ were mothers, $8 \%$ were fathers, $9 \%$ were grandparents, and $10 \%$ were other relatives or foster parents. Seventyone percent of the parents reported being single. Fifty-five percent reported being unemployed, with $26 \%$ having less than a high school education, $31 \%$ holding a high school diploma or equivalent, and $43 \%$ reporting at least some college experience or vocational school training. Reports showed an average of three children per household $(S D=1.6)$. Caregivers who had two or more children in the program were asked to rate only one of their children. The present sample was composed of English-speaking caregivers only. The demographic composition of the participating Head Start centers matches national proportions for urban Head Start programs, with annual income for $90 \%$ of the families below $\$ 12,000$ and most families (64\%) with annual incomes below $\$ 9,000$.

\section{Measures}

Family involvement. Family members' involvement in children's education was measured using the Family Involvement Questionnaire (FIQ; Fantuzzo et al., 2000). This instrument is a multidimensional rating scale that asks primary care providers of young children (i.e., parents, other family members, or legal guardians) to indicate the nature and extent of their involvement in their children's early educational experiences. The FIQ was developed 
in partnership with parents and early childhood teachers in a large urban school district in the Northeast, and is composed of 42 Likert-type items (Rarely, Sometimes, Often, Always). Analyses of the FIQ revealed three parent involvement dimensions: School-Based Involvement, Home-Based Involvement, and HomeSchool Conferencing (Cronbach's $r=.85, .85$, and .81 , respectively). The School-Based Involvement dimension (12 items) is defined by activities and behaviors that parents engage in at school to benefit their children (e.g., volunteering in the classroom, going on class trips, meeting other parents to plan events). HomeBased Involvement (13 items) includes behaviors reflecting active promotion of a learning environment at home for children (e.g., creating space for learning activities at home, providing learning opportunities for the child in the community). Home-School Conferencing (11 items) describes communication behaviors between parents and school personnel about a child's educational experiences and progress (e.g., talking with the child's teacher about learning difficulties and accomplishments, discussing with the child's teacher ways to promote learning at home). Concurrent validity was demonstrated through significant correlations between the three self-report dimensions of the FIQ and documented parent volunteer experiences in Head Start (Fantuzzo et al., 1999).

Approaches to learning. This multidimensional construct was assessed using the Preschool Learning Behaviors Scale (PLBS; McDermott, Green, Francis, \& Stott, 1996), a teacher-report measure of preschool children's approaches to learning. Teachers are asked to rate how often a child exhibits particular behaviors for 29 Likert-type items (Most Often Applies, Sometimes Applies, or Doesn't Apply). This instrument yields three reliable learning behavior dimensions: Competence Motivation, Attention/Persistence, and Attitude Toward Learning. The 11 items on the Competence Motivation dimension reflect a child's curiosity about learning activities, as well as their motivation to understand and succeed in those activities. The Attention/Persistence dimension comprises 9 items related to a child's ability to attend to relevant stimuli and persevere with difficult tasks. The 7 items on the Attitude Toward Learning dimension focus on a child's general demeanor in learning activities, and the way in which they interact with peers and adults in those learning activities. Convergent and divergent validity for the nationally normed scale have been established (McDermott, Leigh, \& Perry, 2002). This scale has been validated for use with a Head Start population (Fantuzzo, Perry, \& McDermott, in press). Analyses yielded the same three-factor solution that was derived from the national standardization sample. Internal consistency was acceptable for the three learning behavior dimensions ( $r=.87, .88, .78$, respectively). Multimethod, multisource validity analyses further substantiated the PLBS dimensions for use with this population of preschool children (see Fantuzzo et al., in press).

Classroom problem behaviors. The Conners' Teacher Rating Scale-28 (CTRS-28; Conners, 1990) is a short form (28-item) version of the CTRS-39, and includes three subscales used to characterize patterns of troublesome child behavior during classroom activities: Conduct Problems (12 items), Hyperactivity ( 8 items), and Inattention/Passivity ( 5 items). The Conduct Problems subscale assesses the degree to which children are prone to temper outbursts, impudence, pouting, and oversensitivity to criticism. The Hyperactivity subscale consists of items measuring restlessness, impulsivity, and demanding behavior. The Inattention-Passivity subscale àssesses distractibility, passivity, and difficulty in finishing tasks. Each item is rated on a 4-point scale (Not at All, Just a Little, Pretty Much, and Very Much).

Standardized scores used in the present study were derived from a factor analysis conducted with data from a large ethnically and geographically diverse sample of preschool children (including 340 African American Head Start children), where the original factor structure was replicated. Reliability for this norm sample was high (for the Conduct Problems $r=.91$, Hyperactivity $r=.90$, and Inattentive-Passive $r=.80$ ). Concurrent validity was established for these dimensions through 
independent observation and teacher and parent ratings of children's social competency (Fantuzzo et al., 2000).

\section{Receptive vocabulary skills.} Children's receptive vocabulary skills were assessed using the Peabody Picture Vocabulary Test-Third Version (PPVT-III; Dunn \& Dunn, 1997). This test has 204 items designed to assess receptive vocabulary for individuals aged 2.5 years through adulthood. The PPVTIII was nationally standardized on a stratified normative sample of 2,000 children and adolescents. Raw scores can be converted to agereferenced standard scores with a mean of 100 . Internal consistency is reported in terms of Spearman-Brown split-half reliability coefficients, and range from .92-.98. Test-retest reliability for a 1-month interval calculated on 226 children in four different age groups ranged from .91-.93. Construct as well as criterionrelated validity was demonstrated through correlations between the PPVT-III and the Wechsler VIQ, PIQ, and FSIQ (.82-.92), the KBIT (.62-.82), and the OWLS (.63-.83). The standardization sample included adequate representation for African American preschool children. The PPVT-III was selected by the Head Start Bureau as an outcome measure for the longitudinal study of its Family and Child Experiences Survey (FACES; U.S. Department of Health and Human Services, 2001).

\section{Procedures}

Data collection procedures were part of a larger partnership effort between the University of Pennsylvania and the school district. Participants were recruited from eight central city Head Start classrooms. There were three aspects to the data collection effort: (a) obtaining data from preschool children's primary caregivers in the late fall, (b) obtaining data from participant children's teachers in the late spring, and (c) gathering independent child assessment data in the late spring. Prior to fall data collection, research team members met with parents and teachers individually to explain the purpose of the study and to clarify issues of confidentiality, informed consent, and data collection procedures. Research team members distributed questionnaire packets consisting of a brief demographic questionnaire and the FIQ to one parent or other primary caregiver per family (where primary caregiver was defined as an adult with whom the child lives and who has significant caregiving responsibility for the child). This initial data collection occurred after the first 3 months of the Head Start year, a time in which parent involvement programming activities were fully underway in the Head Start centers. The participation rate for caregivers was $92 \%$. In late spring (6 months later), teachers were asked to complete the classroom behavior measures (PLBS and CTRS-28) on students for whom parental permission was obtained. Teacher participation was $100 \%$. Independent assessment data (PPVT-III) were then gathered by school psychology doctoral students, who were blind to the research questions.

\section{Data Analysis}

To determine the relationship between the three dimensions of the FIQ assessed in the fall of the year and the three outcome measures assessed at the end of the year, correlational analyses were conducted. First, the nature of bivariate relationships was explored to provide a simple description of the relations between the FIQ dimensions and the PLBS, CTRS-28, and PPVT-III. Subsequently, canonical correlation analyses were conducted to investigate the multivariate relationships between the FIQ assessed in the fall and the two multidimensional measures of children's competencies (the PLBS and the CTRS-28) assessed in the late spring. As recommended by Weiss (1972), canonical variance analysis was chosen as the multivariate data analytic strategy, because it is especially well suited to examine the complex interactions between two sets of multidimensional domains (e.g., family involvement and classroom approaches to learning). When significant bi-multivariate relationships were found through canonical analyses, linear multiple regression analysis was used to further examine how the FIQ dimensions related to classroom learning behaviors and classroom conduct at the end of the year. Multiple regression analysis was also conducted to assess the relations between the 
Table 1

Descriptive Statistics for FIQ Dimensions as a Function of

Demographic Variables $(N=130)$

\begin{tabular}{|c|c|c|c|c|c|c|}
\hline \multirow[b]{3}{*}{ Variable } & \multicolumn{6}{|c|}{ FIQ Dimension ${ }^{\mathrm{a}}$} \\
\hline & \multicolumn{2}{|c|}{ Home-Based } & \multicolumn{2}{|c|}{ School-Based } & \multicolumn{2}{|c|}{ Conferencing } \\
\hline & $M$ & $S D$ & $M$ & $S D$ & $M$ & $S D$ \\
\hline \multicolumn{7}{|l|}{ Caregiver Education Level } \\
\hline Greater than high school & 47.4 & 9.0 & 46.6 & 7.6 & 42.8 & 9.0 \\
\hline High school/GED & 45.9 & 8.1 & 49.6 & 7.8 & 45.3 & 9.3 \\
\hline Less than high school & 44.3 & 10.9 & 49.7 & 7.8 & 46.7 & 6.5 \\
\hline \multicolumn{7}{|l|}{ Caregiver Employment Status } \\
\hline Employed part or full-time & 47.3 & 9.0 & 48.0 & 7.9 & 43.6 & 9.5 \\
\hline Unemployed & 44.7 & 9.2 & 48.8 & 7.8 & 45.6 & 7.9 \\
\hline \multicolumn{7}{|l|}{ Child sex } \\
\hline Male & 44.2 & 10.1 & 46.6 & 7.1 & 43.3 & 8.1 \\
\hline Female & 47.8 & 8.3 & 49.8 & 8.4 & 45.6 & 9.5 \\
\hline
\end{tabular}

Note. Values are $T$-scores.

"Names of FIQ dimensions have been abbreviated for ease of presentation.

FIQ dimensions and receptive vocabulary levels at the end of the year.

\section{Results}

A series of two-way MANOVAs was computed to determine if there were differences in the FIQ dimensions as a function of caregiver education, caregiver employment status, and child sex.' The variable for caregiver education was comprised of three levels: parents with less than a high school education, those with a high school diploma or GED equivalent, and those with greater than high school education. Employment status consisted of two levels (employed full or part-time and unemployed). There were no significant multivariate relationships found between family involvement dimensions and these demographic variables; therefore, these demographic variables were not used as control covariates in subsequent analyses (see Table 1 for descriptive statistics of these variables).

\section{Relationships Between Family Involvement Dimensions and Child Outcomes}

The simple bivariate correlation matrix revealed (see Table 2) that 16 out of the 21 possible correlations were statistically significant in the hypothesized directions with 13 of these correlations at a $p<.01$ level of significance or greater. For a bi-multivariate examination of the FIQ and the selected classroom competencies, two canonical correlations were calculated between the FIQ and the PLBS and the CTRS-28 scales, respectively. These analyses fulfilled two important objectives beyond simple bivariate analyses. First, they provided an overall test of the significance of the multivariate relationship between the FIQ and each of the two sets of multidimensional constructs explored. Second, they provided an understanding of the nature of the relationship be- 
Table 2

Bivariate Correlations of FIQ Dimensions With Children's Outcome Measures $(N=130)$

\begin{tabular}{lccc}
\hline & \multicolumn{3}{c}{ Family Involvement (FIQ) $^{\mathrm{a}}$} \\
& School-Based & Home-Based & Conferencing \\
Outcome Variable & & & \\
\hline $\begin{array}{l}\text { Approaches to Learning (PLBS) } \\
\text { Competence Motivation }\end{array}$ & $.23^{* *}$ & $.35^{* * * *}$ & $.23^{* *}$ \\
Attention \& Persistence & $.25^{* * *}$ & $.36^{* * * *}$ & .17 \\
Attitude Toward Learning & $.25^{* * *}$ & $.30^{* * *}$ & .12 \\
Classroom Problem Behavior (CTRS-28) & & & \\
Conduct Problems & $-.29^{* * *}$ & $-.30^{* * *}$ & $-.18^{*}$ \\
Hyperactivity & -.17 & $-.24^{* *}$ & -.09 \\
Inattention/Passivity & $-.20^{*}$ & $-.20^{*}$ & -.14 \\
Receptive Vocabulary Skills (PPVT-III) & $.32^{* * * *}$ & $.41^{* * * *}$ & $.24^{* *}$ \\
\hline
\end{tabular}

${ }^{\mathrm{N}}$ Names of FIQ dimensions have been abbreviated for ease of presentation.

${ }^{*} p<.05 .{ }^{* *} p<.01{ }^{* * *} p<.001{ }^{* * * *} p<.0001$.

tween the two sets of variables. Each significant canonical correlation reflects variate pairs with distinctive features shared by both sets. These pairs are defined by the highest loading variables from each set.

Learning behaviors. Canonical variance analysis indicated a significant bi-multivariate relationship between dimensions of family involvement assessed in the fall and classroom learning behaviors at the end of the year (Wilks's $\Lambda=.82, F[9,301]=2.9$, $p<.01)$. One significant canonical correlation (canonical $R c=.4, p<.01$ ) yielded a canonical variate pair named Engagement. The canonical variate pair is labeled according to the pattern of the highest loadings from each multivariate construct. Table 3 displays the loadings based on the variate pair for the significant canonical relationship. The greatest overlap in the Engagement variate pair was between the FIQ Home-Based Involvement dimension and the PLBS Competence Motivation and Attention/Persistence dimensions.
Because canonical variance analysis revealed a significant canonical relationship between the FIQ and the PLBS, three separate multiple regression analyses for each of the three PLBS factors were completed (Table 4). Simultaneous regression of the three fall FIQ dimensions on spring PLBS dimensions revealed significant overall relationships for Competence Motivation $(F[3,126]=6.7, p<$ $.001)$, Attention/Persistence $(F[3,126]=6.7$, $p<.001$ ), and Attitude Toward Learning ( $F$ $[3,126]=5.1, p<.01)$. Home-Based Involvement emerged as the only significant predictor of all three dimensions of the PLBS when FIQ dimensions were considered simultaneously.

Classroom behavior problems. $\mathrm{Ca}$ nonical variance analysis indicated a significant bi-multivariate relationship between dimensions of family involvement assessed in the fall and types of classroom behavior problems assessed at the end of the year (Wilks's $\Lambda$ $=.86, F[9,301]=2.1, p<.05)$. One significant canonical correlation (canonical $R c=.35$, 
Table 3

Canonical Structure of FIQ Dimensions With PLBS Dimensions $(N=130)$

\begin{tabular}{ll}
\hline \multirow{2}{*}{ Variable } & Canonical Variate Set \\
\cline { 2 - 2 } & Engaged \\
\hline
\end{tabular}

Family Involvement (FIQ)

Home-Based Involvement

School-Based Involvement

Home-School Conferencing

Approaches to Learning (PLBS)

Competence Motivation

Attention/Persistence

.92

Positive Attitude Toward Learning

.78

Note. Loadings $\geq .80$ are considered appreciable and are italicized.

$p<.05)$ yielded a canonical variate pair named Cooperative. Table 5 displays the loadings based on the variate pair for the significant canonical relationship. The Cooperative canonical variate pair reveals noticeably high positive loadings for the FIQ School-Based Involvement and Home-Based Involvement dimensions, with a markedly low loading for the CTRS-28 Conduct dimension.

Simultaneous regression of the three fall FIQ dimensions on each of the CTRS-28 factors revealed a predictive pattern consistent with canonical variance analysis. Three separate multiple regression analyses for each of the three CTRS-28 factors were completed (Table 4). A significant overall relationship was found between the FIQ predictor variables and two of the CTRS-28 factors, Conduct ( $F[3$, $126]=5.7, p<.001)$ and Hyperactivity $(F[3$, $126]=2.8, p<.05$ ). Home-Based Involvement was the only significant predictor of these two CTRS-28 dimensions.

Receptive vocabulary. Simultaneous multiple regression of the fall FIQ dimensions on spring PPVT-III scores revealed a significant overall relationship, $(F[3,126]=10.0, p$ $<.0001$ ). Again, Home-Based Involvement was the only significant predictor of children's receptive vocabulary skills at the end of the year (see Table 4).

\section{Discussion}

Overall, this study demonstrated that parent involvement dimensions were differentially associated with student learning and classroom behavioral adjustment outcomes for a sample of predominantly African American, urban Head Start children. Home-Based Involvement activities, such as reading to a child at home, providing a place for educational activities, and asking a child about school, evidenced the strongest relationships to later preschool classroom competencies. These activities were related to children's approaches to learning, especially motivation and attention/persistence, and were found to relate positively to receptive vocabulary. Further, higher levels of HomeBased Involvement were associated with significantly lower levels of classroom behavior problems. The School-Based Involvement and Home-School Conferencing dimensions showed some significant bivariate relations with end of year outcome variables; however, when considered simultaneously with the Home-Based Involvement 


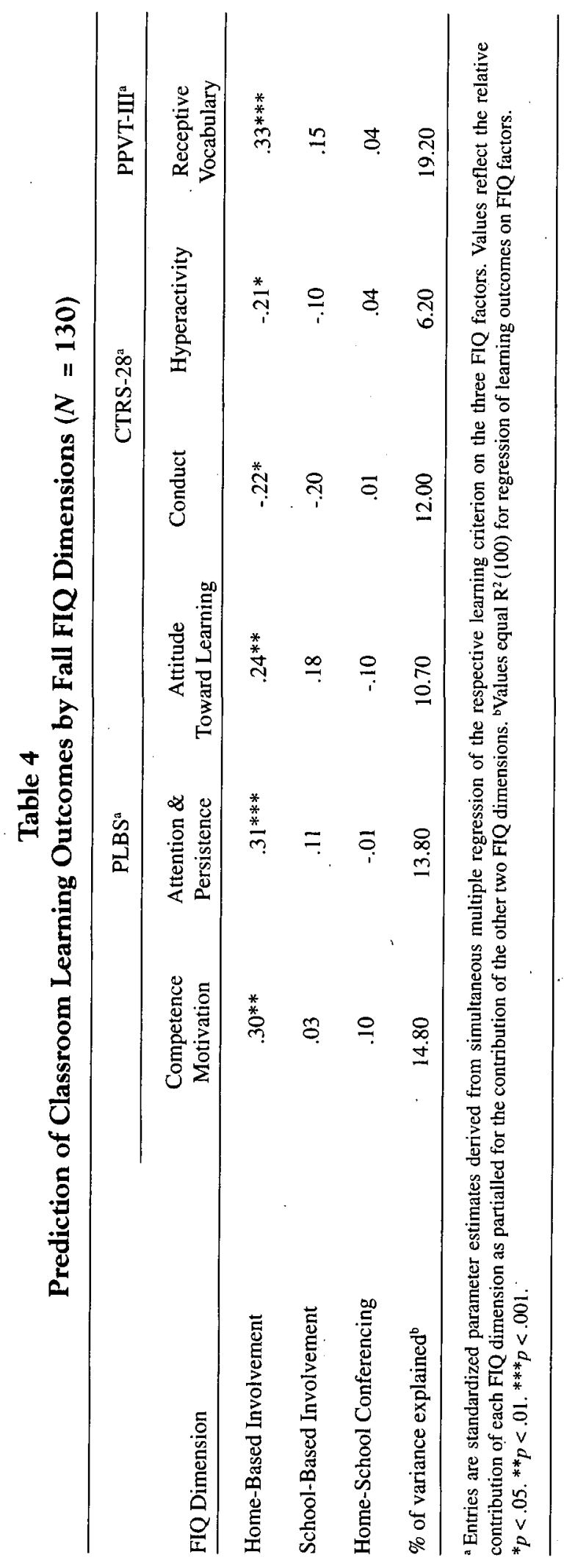


Table 5

Canonical Structure of FIQ Dimensions With CTRS-28

Dimensions $(N=130)$

Canonical Variate Set

Variable

Cooperative

Family Involvement (FIQ)

Home-Based Involvement

School-Based Involvement

Home-School Conferencing

Classroom Problem Behaviors (CTRS-28)

Conduct Problems

Hyperactivity

Inattention/Passivity

$-.66$

Note. Loadings $\geq .80$ are considered appreciable and are italicized.

dimension, their relative contributions to predicting children's outcomes were significantly less.

The findings from the present study on the relationship between Home-Based Involvement and various child competencies adds to the literature by highlighting the importance of parental involvement in supporting children's learning in the home environment. Dickinson and DeTemple (1998) found that mothers of preschoolers who provided home support for literacy had children who performed better on measures of language and literacy in kindergarten and first grade. Using a composite score from a questionnaire on home literacy activities, Mantzicopoulos (1997) also demonstrated that literacy-focused home-involvement behaviors were related to later achievement. Further, she showed that this involvement was predictive of children's selfefficacy beliefs and school adjustment. A relative weakness in these studies was the use of unidimensional, unscaled surveys or raw composite scores to assess parental activities in the home environment. Fantuzzo and colleagues (1999) demonstrated, using a multidimensional scale (FIQ) with an urban ethnic, minority
Head Start sample, that the dimension of home involvement behavior was related significantly to children's peer play competencies relative to other dimensions of parent involvement. The present study extends the prior cross-sectional study by substantiating the relationship between positive home-based parental involvement and additional sets of preschool competencies outcomes assessed at the end of the Head Start year. This study not only provided evidence that home-based involvement is important, but it revealed that the Home-Based Involvement dimension was superior to the other dimensions in its relationship to relevant preschool competencies for urban Head Start children.

The present study also demonstrated that School-Based Involvement loaded appreciably on a significant canonical variate pair termed Cooperative. This relationship reflected a shared contribution with Home-Based Involvement to markedly low classroom conduct problems. However, as mentioned above, when forced to compete with Home-Based Involvement in a linear multiple regression, HomeBased Involvement was superior. Using the FIQ in a previous cross-sectional study, 
Fantuzzo and colleagues (1999) demonstrated that School-Based Involvement was linked to lower levels of disruptive play behaviors in the classroom relative to other FIQ dimensions. The present study extends these findings by showing that School-Based family involvement behaviors were associated with decreased behavior problems in the classroom along with Home-Based Involvement at the end of the Head Start year. However, when compared to School-Based Involvement, Home-Based Involvement was superior. It is hypothesized that the visible presence of parents or family members in school creates a concrete connection for children between the two environments (Fantuzzo et al., 1999). This link may be associated with the transfer of both parental authority and social support to the school context (Parker et al., 1999; Wentzel, 1999).

The Home-School Conferencing dimension, when considered simultaneously with the Home-Based Involvement and School-Based Involvement dimensions, was a relatively weak contributor to bi-multivariate relationships with the multidimensional constructs of children's approaches to learning and classroom conduct. Although home-school conferencing is recognized in the parent involvement literature as representing distinctive and dynamic exchanges between teachers and parents about children's progress (Epstein, 1995), there is little empirical study of this dimension. There are a number of aspects of the Home-School Conferencing dimension hypothesized to influence the contribution of this dimension to child outcomes. First, in contrast to more direct classroom volunteering activities, teacher-parent conferences (including oneto-one visits, notes, and telephone calls) may be less visible to the child and therefore have a less direct influence on behavior. Second, the impact of this dimension may be a function of the quality and reciprocal nature of the exchanges between parent and teacher (Christenson, 1999). Significant cultural and socioeconomic differences between the parents and teachers can affect the mutual benefits of these interactions. In a prior study using the FIQ (Fantuzzo et al., 2000), it was found that the Home-School Conferencing dimension was associated with parental education, with higher levels of education related to higher levels of conferencing. Future research is needed to explore these aspects of this important dimension.

The findings of the present study are qualified by the target population and primary use of maternal report. The sample for this study was a low-income, predominantly African American urban Head Start population. Future studies should explore if the relationships found in this study between family involvement dimensions and child outcomes are evident with other populations (e.g., rural and/ or suburban samples, families from other ethnic groups). Additionally, future research should include other sources of data documenting these distinct dimensions of involvement such as teacher reports and independent observations conducted at home and school to enhance understanding of the associations between dimensions of involvement and school readiness competencies. Moreover, because the primary respondents in this present study were mothers, future research should investigate if there are differences in the amount and type of involvement between mothers and fathers and if these differences are associated with different patterns of child outcomes (Gadsden \& Ray, 2002).

The present study was also limited by the relatively short 6-month time frame. In the future, studies should investigate family involvement dimensions across longer time periods. It is particularly critical to examine the quality of the relationship between families and schools as children transition to kindergarten and the primary grades (Early \& Pianta, 1998; Pianta, Rimm-Kaufman, \& Cox, 1999). Early and Pianta (1998) found that contact between schools and families was actually one of the least used practices involved in children's transition to this new school context. Future studies on parent involvement should continue to investigate how parent involvement changes across school contexts and over time.

The findings of the current study have general implications for early childhood educational policy and practice. All three of the parent involvement dimensions examined in 
this study could be potentially influenced by school climate and teacher practices (Epstein, 1991; Smith, Connell, Wright, Sizer, \& Norman, 1997). School practices have been found to be a stronger predictor of parent involvement than parents' education level, income status, or ethnic background (Christenson, 1999; Eccles \& Harold, 1996). To enhance involvement, school psychologists and other school personnel should target barriers that have been found to adversely affect home-school partnerships. They include: lack of training for school personnel in partnering with parents, lack of effective interpersonal communication skills (for teachers and parents), conflict in perception of parents' roles, failure to inspect school practices that do not meet families' needs (e.g., deficiency model of families, contact only in crises), and a narrow approach to the roles that parents can play in their children's education (Christenson, 1999, 2004; Epstein, 1990; Melton, Limber, \& Teague, 1999; Parker et al., 2001).

Another general implication of the present findings involves the need to understand more about the extent and nature of family involvement in early childhood education. Family involvement data in this study were collected during the first third of the school year, a time when, presumably, dialogue between teachers and parents should be intense and dynamic. However, our findings demonstrated that both school-based involvement and home-school conferencing were not as important as home-based involvement in predicting children's end of the year outcomes, standing in contrast to other literature that document their value. Perhaps in practice, this initial contact is less substantial, and therefore does not affect significantly children's progress. Parent involvement assessments should be conducted at multiple times during the year to track changes in dimensions of involvement across time and relate these changes to child outcomes.

School psychologists are uniquely qualified to help larger systems (schools or school districts) extend their understanding of family involvement and address barriers to genuine home-school partnerships. Serving in a con- sultant role, school psychologists are in an optimal position to foster connections between teachers and family members. Christenson and Sheridan (2001) indicate concrete steps that school psychologists can take to promote twoway communications and shared decision making at a system-wide level. For example, school psychologists can advocate for system change, create new policies and practices that improve home-school communications and relationships, and work directly with teachers and parents to foster conjoint problem solving (Sheridan, Kratochwill, \& Bergan, 1996). Studies such as the present one provide evidence to indicate the benefits of creating more dynamic transactions between home and school.

In sum, the present study revealed important relationships between the multidimensional construct of parent involvement and preschool classroom competencies with ethnic minority, urban, low-income children. Through continued attention to the familyschool relationship, educators can build more effectively on the competencies that children and their families bring to the preschool classroom context. It is clear that parents want to be more involved in their children's education (Christenson, Hurley, Sheridan, \& Fenstermacher, 1997), but it is largely up to schools to explicitly recognize, through attitudes, policies, and practices, that parents are fundamental partners in the education and development of their children.

\section{Footnotes}

'Marital status did not have sufficient variability to use in a multivariate analysis of variance (i.e., $87 \%$ of the sample was single, divorced, widowed, or separated).

\section{References}

Bronfenbrenner, U. (1992). Ecological systems theory. In R. Vasta (Ed.), Six theories of child development: Revised formulations and current issues (pp. 187-249). Ithaca, NY: Cornell University Department of Human Development and Family Studies.

Christenson, S. L. (1999). Families and schools: Rights, responsibilities, resources, and relationships. In R. C. Pianta \& M. J. Cox (Eds.), The transition to kindergarten (pp. 143-177). Baltimore, MD: Paul H. Brooks Publishing Co. 
Christenson, S. L. (2004). The family-school partnership: An opportunity to promote the learning competence of all students. School Psychology Review, 33, 83-104.

Christenson, S. L., Hurley, C. M.; Sheridan, S. M., \& Fenstermacher, K. (1997). Parents' and school psychologists' perspectives on parent involvement activities. School Psychology Review, 26, 111-130.

Christenson, S. L., \& Sheridan, S. M. (2001). Schools and families: Creating essential connections for learning. New York: Guilford Press.

Conners, C. K. (1990). Conners' Rating Scales manual. Toronto, Canada: Multi-Health Systems.

Dickinson, D. K., \& DeTemple, J. (1998). Putting parents in the picture: Maternal reports of preschoolers' literacy as a predictor of early reading. Early Childhood Research Quarterly, I3, 241-261.

Dunn, L. M., \& Dunn, L. M. (1997). Peabody Picture Vocabulary Test-Third Edition. Circle Pines, MN: American Guidance Services.

Early, D. M., \& Pianta, R. C. (1998, April). Kindergarten transition practices: Relations with teacher and classroom characteristics. Paper presented at the annual meeting of the American Educational Research Association, San Diego.

Eccles, J. S., \& Harold, R. D. (1996). Family involvement in children's and adolescent's schooling. In A. Booth \& J. F. Dunn (Eds.), Family-school links: How do they affect educational outcomes? (pp. 3-34). Mahway, NJ: Lawrence Erlbaum Associates.

Epstein, J. L. (1990). School and family connections: Theory, research, and implications for integrating sociologies of education and family. Marriage \& Family Review, 15, 99-126.

Epstein, J. L. (1991). Effects on student achievement of teachers' practices of parent involvement. In S. B. Silvern (Ed.), Advances in reading/language research: Vol. 5. Literacy through family, community, and school interaction (pp. 261-276). Greenwich, CT: JAI Press.

Epstein, J. L. (1995). School/family/community partnerships: Caring for the children we share. Phi Delta Kappan, 701-712.

Fantuzzo, J., Grim, S., Mordell, M., McDermott, P., Miller, L., \& Coolahan, K. (2001). A multivariate analysis of the revised Conners' Teacher Rating Scale with lowincome, urban preschool children. Journal of Abnormal Child Psychology, 29, 141-152.

Fantuzzo, J., Perry, M. A., \& McDermott, P. A. (in press). Preschool approaches to learning and their relationship to school readiness competencies for low-income children. School Psychology Quarterly.

Fantuzzo, J., Tighe, E., \& Childs, S. (2000). Family Involvement Questionnaire: A multivariate assessment of family participation in early childhood education. Journal of Educational Psychology, 92, 367-376.

Fantuzzo, J., Tighe, E., \& Perry, M. (1999). Relationships between family involvement in Head Start and children's interactive peer play. NHSA Dialog, 3, 6067.

Gadsden, V., \& Ray, A. (2002). Engaging fathers: Issues and considerations for early childhood educators. Young Children, 57, 32-42.

Galper, A., Wigfield, A., \& Seefeldt, C. (1997). Head Start parents' beliefs about their children's abilities, task values, and performances on different activities. Child Development, 68, 897-907.

Griffith, J. (1996). Relation of parental involvement, empowerment, and school traits to student academic performance. Joumal of Educational Research, 90, 33-41.

Kagan, S. L., Moore, E., \& Bredekamp, S. (Eds.). (1995). Reconsidering children's early development and learning: Toward common views and vocabulary. Washington, DC: National Education Goals Panel.

Keith, T. Z., Keith, P. B., Quirk, K. J., Sperduto, J., Santillo, S., \& Killings, S. (1998). Longitudinal effects of parent involvement on high school grades: Similarities and differences across gender and ethnic groups. Journal of School Psychology, 36, 335-363.

Mantzicopoulos, P. Y. (1997). The relationship of family variables to Head Start children's preacademic competence. Early Education \& Development, 8, 357-375.

McDermott, P. A., Green, L. F., Francis, J. M., \& Stott, D. H. (1996). Learning Behaviors Scale. Philadelphia, PA: Edumetric and Clinical Science.

McDermott, P. A., Leigh, N. M., \& Perry, M. A. (2002). Development and validation of the Preschool Learning Behaviors Scale. Psychology in the Schools, 39, 353-365.

Melton, G. B., Limber, S. P., \& Teague, T. L. (1999). Changing schools for changing families. In R. C. Pianta \& M. J. Cox (Eds.), The transition to kindergarten (pp. 179-213). Baltimore, MD: Paul H. Brooks Publishing Co.

National Education Goals Panel. (1997). Getting a good start in school. Washington, DC: Author.

National Research Council. (2001). Eager to learn: Educating our preschoolers. Washington, DC: National Academy Press.

Parker, F. L., Boak, A. Y., Griffin, K. W., Ripple, C., \& Peay, L. (1999). Parent-child relationship, home learning environment, and school readiness. School Psychology Review, 28, 413-425.

Parker, F. L., Piotrkowski, C. S., Baker, A. J., KesslarSklar, S., Clark, B., \& Peay, L. (2001). Understanding barriers to parent involvement in Head Start: A research-community partnership. Early Childhood Research Quarterly, 16, 35-51.

Parker, F. L., Piotrkowski, C. S., Kessler-Sklar, S., Baker, A. J., Peay, L., \& Clark, B. (1997). Parent involvement in Head Start (Executive summary). New York: National Council of Jewish Women Center for the Child.

Pianta, R. C., Rimm-Kaufman, S. E., \& Cox, M. J. (1999). Introduction: An ecological approach to kindergarten transition. In R. C. Pianta \& M. J. Cox (Eds.), The transition to kindergarten (pp. 3-12). Baltimore, MD: Paul H. Brookes Publishing Company.

Reynolds, A. J. (1992). Comparing measures of parental involvement and their effects on academic achievement. Early Childhood Research Quarterly, 7, 441462.

Reynolds, A. J., Mavrogenes, N. A., Bezruczko, N., \& Hagemann, M. (1996). Cognitive and family-support mediators of preschool effectiveness: A confirmatory analysis. Child Development, 67, 1119-1140.

Rimm-Kaufman, S. E., \& Pianta, R. C. (2000). An ecological perspective on the transition to kindergarten: $A$ 
theoretical framework to guide empirical research. Journal of Applied Developmental Psychology, 21, 491-511.

Sheridan, S. M., Kratochwill, T. R., \& Bergan, J. R. (1996). Conjoint behavioral consultation: A procedural manual. New York: Plenum Press.

Slaughter-Defoe, D., \& Brown, E. (1998). Educational intervention and the family: The Chicago tradition in policy and practice. National Head Start Research Quarterly, Spring, 39-111.

Smith, E. P., Connell, C. M., Wright, G., Sizer, M., \& Norman, J. M. (1997). An ecological model of home, school, and community partnerships: Implications for research and practice. Journal of Educational and $P$ sychological Consultation, 8, 339-360.

Sui-Chu, E. H., \& Willms, J. D. (1996). Effects of parental involvement on eighth-grade achievement. Sociology of Education, 69, 126-141.

U.S. Department of Education. (2000, September). Strategic Plan, 2001-2005. Washington, DC: Author.
U.S. Department of Health and Human Services. (1998). Final rule-Head Start Performance Standards, 45 CFR Part 1304, Federal Register, 61, 57186-57227. Washington, DC: U.S. Government Printing Office.

U.S. Department of Health and Human Services. (2001). Head Start FACES: Longitudinal findings on program performance. Third progress report. Washington, DC: Author.

Watkins, T. J. (1997). Teacher communications, child achievement; and parent traits in parent involvement models. The Journal of Educational Research, 91,314.

Wentzel, K. R. (1999). Social-motivational processes and interpersonal relationships: Implications for understanding motivation at school. Journal of Educational Psychology, 91, 76-97.

Weiss, D. J. (1972). Canonical correlation analysis in counseling psychology research. Journal of Counseling Psychology, 19, 241-252.

John Fantuzzo, PhD, is the Diana Riklis Professor of Education in the Policy Research Evaluation and Measurement Program at the University of Pennsylvania. He is a licensed clinical child psychologist whose research focuses on design, implementation, and evaluation of school-and community-based strategies for young, low-income children in highrisk urban settings. He has directed over a decade of funded research in partnership with the Office of Early Childhood Education in the School District of Philadelphia (serving over 22,000 children) and has been involved in population-based studies involving citywide, integrated databases across agencies serving young children. He is PI of a recently awarded NICHD grant designed to develop and evaluate an early childhood curricula integrating empirically validated literacy, numeracy, socioemotional, and approaches to learning components.

Christine McWayne, PhD, is an Assistant Professor of Applied Psychology in The Steinhardt School of Education at New York University. Dr. McWayne is involved in partnership-and community-based research within the Head Start community in New York City. Generally, her research interests include: conceptualizations of family involvement in children's education in low-income communities, helping to establish a whole-child understanding of low-income, preschool children's school readiness competencies, and validating assessment instruments and intervention for low-income, preschool children and their families. Her recent research has focused on the examination of multiple dimensions of school readiness within the context of classroom quality and the social and structural dimensions of urban neighborhoods.

Marlo A. Perry, MS.Ed, is an advanced doctoral student in the School, Community, and Clinical-Child Psychology program at the University of Pennsylvania. She was awarded a student research grant from DHHS -Administration for Children, Youth, and Families to examine the impact of welfare to work mandates on family involvement and on children's outcomes in Head Start. She also earned the Student Poster Award from the American Psychological Association's School Psychology Division in 2000. Her research has focused on the development and implementation of culturally and ecologically valid parent and teacher assessments for Head Start children; family involvement in Head Start and its relation to children's learning and behavioral competencies; and young children exposed to domestic violence. 


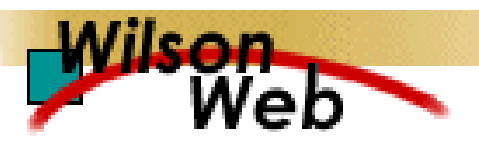

\section{COPYRIGHT INFORMATION}

TITLE: Multiple Dimensions of Family Involvement and Their Relations to Behavioral and Learning Competencies for Urban, Low-Income Children

SOURCE: Sch Psychol Rev 33 no4 2004

WN: 0400400759001

The magazine publisher is the copyright holder of this article and it is reproduced with permission. Further reproduction of this article in violation of the copyright is prohibited. To contact the publisher: http://www.nasponline.org/index $2 . h t m l$

Copyright 1982-2005 The H.W. Wilson Company. All rights reserved. 